\title{
Text(ge)schichten
}

\section{Antonio Tabucchi unterwegs zu Dino Campana, Nietzsche und Orpheus}

\author{
L'alluvione ha sommerso il pack dei mobili, \\ delle carte, dei quadri che stipavano \\ un sotteraneo chiuso a doppio lucchetto. \\ Forse hanno ciecamente lottato i marocchini \\ rossi, le sterminate dediche di Du Bos, \\ il timbro di ceralacca con la barba di Ezra, \\ il Valéry di Alain, l'originale dei Canti Orfici - ... \\ (Eugenio Montale) ${ }^{1}$
}

In Vagabondaggio from the early collection $\mathrm{Il}$ gioco del rovescio, Tabucchi undertakes an oneiric and personal approach to the life and work of the Italian symbolist poet Dino Campana (1885-1932). The text is based on Nietzsche's aphorism "Reisende und ibre Grade" (Menschliches, Allzumenschliches), which establishes five categories of voyagers. Tabuchi uses these as stages in the protagonist's quest for personal aesthetics. The aesthetics itself alludes to major motives in Campana's masterpiece, Canti Orfici.

Die Schrift sei zahlreich oder sie sei nicht, verkündete einst Jacques Derrida. ${ }^{2}$ "Zahlreich" zum einen, weil die Schrift der Texte nicht eingehe in den einen Sinn des Textes, sich nicht in diesem ein- und auflöse, "zahlreich" zum andern, weil jeder Text Lektüre anderer Texte ist. Der Textkörper ist kein abgeschlossener Korpus, sondern auf alle Texte hin offen, die ihm eingeschrieben werden, Texte aus allen Zeiten, allen Gattungen, so dass er eine unendliche Dichte besitzt. "Die Schrift des Textes geht gänzlich in der Lektüre anderer

${ }^{1}$ Eugenio Montale, Satura (Xenia II/14), in: ders., Tutte le poesie. A cura di Giorgio Zampa, Milano: Mondadori, 1990, S. 318. [Das Hochwasser hat die Masse der Möbel, / Schriftstücke und Bilder überflutet, die einen Keller füllten, / der mit doppeltem Schloß gesichert war. / In blinder Verzweiflung haben vielleicht die roten Maroquinlederbände gekämpft, / Du Bos’ zerstörte Widmungen, / der Siegellackstempel mit Ezras Bart, / der Valéry Alains, das Original der Orphischen Gesänge [...]; Übersetzung RDB].

2 Vgl. Jacques Derrida, Dissémination, Paris: Éd. du Seuil, 1972, S. 396. 
Texte auf". 3 Diese Maxime Derridas zu seiner Theorie der sog. 'textuellen Pfropfung'4 beleuchtet, auf die Prosa Antonio Tabucchis angewandt, eine seiner charakteristischsten Seiten. Seine Texte leben von ihren zahllosen Bezügen zur Literatur. "Er macht so aus viel wenig und aus wenig viel”, schrieb Gunde Kurtz bereits Anfang der 90er. "Wenig aus viel, indem er einerseits die Unmenge an Stoff seiner Quellen zusammenschrumpft auf allusive Bemerkungen, kurze Erzählungen, micro-romanzi”. ${ }^{5}$ Viel aus wenig, indem er ein begrenztes Repertoire an wiederkehrenden Motiven und Handlungsmustern mit vorhandener Literatur multipliziere und so eine unendliche Nuancierung seiner Erzählungen erreiche.

Doch auch wenn insbesondere seine Erzählungen und Romane angefüllt sind mit ganzen Borges-Bibliotheken an literarischen, kulturellen und epistemologischen Anspielungen, werden sie damit noch keineswegs zum intertextuellen Kultur-Puzzle für eine wissende Minderheit, löst sich ihr Textkörper nicht völlig in der Lektüre anderer Texte auf. Als homogenes Ganzes auftretend bleiben sie stets einer breiteren Leserschicht zugänglich und sind bereits mit Blick auf eine mögliche Dekodierung auf unterschiedlichen Ebenen hin verfasst. Damit wurden sie auch zum Ausdruck jener "postmodernen Lust am Erzählen”, für die Tabucchi (*1943) und andere Autoren seiner Generation wie Daniele del Giudice (*1943) und Andrea de Carlo (*1952) zu Beginn der 80er Jahre so enthusiastisch als "giovani scrittori" von der italienischen und bald auch internationalen Kritik begrüßt wurden. (Nun sind die “jungen Autoren” von einst längst zu modernen Klassikern geworden und stehen wiederum selbst in der Kritik der nächsten Generation. ${ }^{6}$ )

Am Beispiel der kurzen frühen Erzählung Vagabondaggio (Vagabundenleben) aus dem Band Il gioco del rovescio (Das Umkehrspiel) lässt sich Tabucchis Prinzip der Verschachtelung der unterschiedlichsten poetologischen, intertextuellen und narrativen Strategien besonders gut aufzeigen, stellt sie doch eine Art intertextueller Zeitreise dar, die von den eigenen Texten über die Gedichte des italienischen Fin-de-Siècle-Lyrikers Dino Campana und Nietzsches Kunstphilosophie bis hin zur antiken orphischen Mystik führt. So muss auch die folgende Inter-

3 Jacques Derrida, Positionen. Gespräche mit Henri Ronse, Julia Kristeva, Jean-Louis Houdebine, Guy Scarpetta. Hrsg. von Peter Engelmann. Aus dem Französischen übersetzt von Dorothea Schmidt. Dt. Erstausgabe, Graz [u.a.]: Böhlau, 1986, S. 34.

4 Siehe hierzu Sarah Kofman, Derrida lesen. 2. durchgesehene Auflage, Wien: Passagen-Verlag, 2000, S. 13-21.

5 Gunde Kurtz, Die Literatur im Spiegel ihrer selbst. Italo Calvino, Antonio Tabucchi - zwei Beispiele, Frankfurt a. M. u. a.: Peter Lang, 1992, S. 270. Siehe auch Flavia Brizio-Skov, Antonio Tabucchi: navigazioni in un arcipelago narrativo, Cosenza: L. Pellegrini, 2002.

${ }^{6}$ Vgl. Irina O. Rajewsky, Intermediales Erzählen in der italienischen Literatur der Postmoderne. Von den 'giovani scrittori' der 80er zum 'pulp' der 90er Jahre, Tübingen: Narr, 2003. Zum Generationswechsel durch die sog. 'pulp'-Literatur am Beispiel einer ihrer Protagonisten siehe auch: Roberto Di Bella, "Tiziano Scarpa (Profilo d'autore)", in: Italienisch. Zeitschrift für italienische Sprache und Literatur 50, 2003, 2, S. 110-119. 
pretation durch die unterschiedlichsten Schichten dringen, um die zunächst unscheinbar wirkende Oberfläche der Erzählung als Reproduktion oder Variation von Signifikanten mehrerer, 'absenter' Textebenen zu begreifen ${ }^{7}$, denn vielfach operiert Tabucchi in seinen Texten im Sinne einer unmarkierten Intertextualität. Als immense "Akkumulation textueller Erfahrung"8 wird so die vorliegende Erzählung nicht nur zur Hommage an eine der enigmatischsten Figuren der italienischen Lyrik des 20. Jahrhunderts, sondern entpuppt sich darüber hinaus als literarische Verdichtung der Kerngedanken der Poetik Dino Campanas und ist zudem ein Sammelbecken fast sämtlicher von Tabucchi selbst, seit dem Roman Piazza Italia (1975), verwendeten Topoi und Erzählverfahren.

Von der Oberfläche aus betrachtet führt die 'Geschichte' - im Sinne der Narratologie Genettes als "Gesamtheit der erzählten Ereignisse"9 - zunächst zurück in das Jahr 1906 bzw. in die Emilia-Romagna, irgendwo zwischen Bologna und Modena entlang der sich schnurgerade durch diese Landschaft ziehenden Via Emilia. Hier fährt der Zug, in dem der Protagonist der Erzählung sitzt: Dino Artista, ein junger Mann von 21 Jahren, der als Vagabund und Jongleur unterwegs ist. In seinem Abteil macht er die Bekanntschaft eines älteren Mannes, eines Viehhändlers, der sich gerade auf dem Weg zum Markt nach Modena befindet. Der im Folgenden nur als "der Makler" (“il Sensale”) bezeichnete Mann, “ein beleibter, älterer Herr mit einer Goldkette auf der Weste"10, dessen Namen man nicht erfährt, nimmt sich seines unbeholfenen jungen Mitreisenden an, dies auch, weil er ihn an den eigenen, vier Jahre zuvor an einem Fieber verstorbenen Sohn erinnert. Er lädt Dino, der dem Sensale gegenüber seinen Nachnamen als Pseudonym bezeichnet ("Und da es ein Künstlername ist, habe ich Artista gewählt”, UK 158), ohne dabei seine eigentliche Identität mitzuteilen, und der nach eigener Angabe ohne Ziel reist, in Modena zum Essen ein, zeigt ihm die Stadt und führt ihn abends gar in ein Bordell. Tags darauf macht er ihn mit seinem Freund Regolo bekannt, einem fahrenden Händler, mit dem der Junge seine

\footnotetext{
7 Zur Problematik der Markierung intertextueller Verweise vgl. Jörg Helbig, Intertextualität und Markierung. Untersuchungen zur Systematik und Funktion von Intertextualität, Heidelberg: Winter, 1996, S. 18-36.

8 Renate Lachmann, Gedächtnis und Literatur. Intertextualität in der russischen Moderne, Frankfurt a. M.: Suhrkamp, 1990, S. 74.

9 "Ich schlage vor, [...] das Signifikat oder den narrativen Inhalt Geschichte zu nennen [...], den Signifikanten, die Aussage, den narrativen Text oder Diskurs Eræ̈ählung im eigentlichen Sinne, während Narration dem produzierenden narrativen Akt sowie im weiteren Sinne der realen oder fiktiven Situation vorbehalten sein soll, in der er erfolgt" (Gérard Genette, Diskurs der Eržählung, München/Wien: Fink, ${ }^{21998, ~ S . ~ 16) . ~}$

10 Antonio Tabucchi, "Vagabundenleben", in ders., Das Umkehrspiel. Übersetzt von Dagmar TürckWagner und Karin Fleischanderl, München/Wien: Hanser, 2000, S. 157-168, S. 158; diese Ausgabe wird im folgenden zitiert als UK. Die italienische Originalausgabe des Bandes erschien erstmals 1981 beim Verlag 'Il Saggiatore' in Mailand. Vagabondaggio ist jedoch erst in der erweiterten zweiten Auflage enthalten (A. T., Il gioco del rovescio, Mailand: Feltrinelli, 1986, S. 145-153).
} 
Reise fortsetzen wird. Die Erzählung endet dann (nach einigen Zwischenetappen) auf der Burgruine von Canossa, von wo aus Dino seinen weiteren eigenen Weg überblickt, der ihn Richtung Norden nach Mailand und in die großen europäischen Metropolen führen wird.

Soweit in knappen Zügen der Inhalt. Doch muss die Interpretation zunächst an ganz anderer Stelle ansetzen. Denn wenn auch Tabucchi oftmals einer intertextuellen Verschleierungstaktik folgt, so lässt er seine Leser dabei nie ganz im Dunkeln. Die Erzählung sei ein Ritual, so Tabucchi einmal, und der Autor dessen Zelebrant. Hierbei gelte es einen Geheimnisanteil aufrecht zu erhalten, doch lebe das Ritual ebenso von der Enthüllung. Es gebe Dinge, die es der (Leser-)Gemeinde mitzuteilen gelte, und um sie dem Ritual nicht zu entfremden, müssten die Zuschauer die Symbole erkennen. ${ }^{11}$ So legt Tabucchi Fährten, die man weiterverfolgen kann, aber nicht muss. Für ein komplexeres Textverständnis ist diese 'Spurensuche' jedoch unerlässlich und sie hat in diesem Fall vom Ende auszugehen (ganz entsprechend der auf ein Kinderspiel anspielenden Titelgeschichte des gesamten Bandes Das Umkehrspiel), nämlich von der der Erzählung beigefügten Anmerkung:

Diese Erzählung ist rein fiktiv. Auch wenn Regolo Orlandini in den "Erklärungen" Campanas vorkommt, die von Doktor Pariani aufgezeichnet wurden, ist er hier eine frei erfundene Figur. Das einzige nichtfiktive Element sind die Verse Dino Campanas und die Städte, die Orte, die Via Emilia. A.T.

Diese unscheinbare Anmerkung ${ }^{12}$ wird sich als 'Schlüssel' zur Erzählung erweisen; zumindest gelangt man mit ihr um einige Türen weiter, bei richtiger Anwendung. Denn der kleine Text ist nicht unproblematisch, da die Informationen darin - wie dies bei den von Tabucchis zahlreich eingesetzten Paratexten (seien es Vor-, Nachworte, Anmerkungen, Widmungen und Motti) meist der Fall ist "zwar hilfreich, aber nur rudimentär"13, selbst verschlüsselt sind und damit letztlich mehr Fragen aufwerfen können als sie beantworten ${ }^{14}$ : In welcher Beziehung

11 "Il racconto è un rituale, un rito che viene celebrato e il celebrante è lo scrittore. Nel rito è necessario mantenere una parte di mistero, ma bisogna anche svelare, ci sono delle cose che vanno detti ai fedeli, ossia a loro che leggono i racconti. [...] Per non sentirsi estranei al rito, gli spettatori devono risoncosere i simboli" (Andrea Borsari, "Cos'è una vita se non viene raccontata?" Conversazione con Antonio Tabucchi”, in: Italienisch. Zeitschrift für italienische Sprache und Literatur 23, 1991, 26, S. 2-23, S. 12 f.

12 Die Anmerkung lautet im Orginal: "Questo racconto è interamente immaginario. Anche se la figura di Regolo Orlandini è rammentata nelle confessioni raccolte dal dottor Pariani, qui è usata in modo del tutto arbitrario. Le uniche cose non immaginarie sono i versi di Dino Campana; e poi le città, i luoghi, la Via Emilia" (Tabucchi, Il gioco del rovescio, wie Anm. 10, S. 153).

13 Kurtz, Die Literatur im Spiegel ihrer selbst (wie Anm. 5), S. 298.

14 Zur Funktion der Paratexte siehe weiter Kurtz, Die Literatur im Spiegel ibrer selbst (wie Anm. 5), S. 288f. und S. 299-302. Zum Aspekt der Metafiktionalität bei Tabucchi siehe auch Sylvia Setzkorn, Vom Erzählen eræäblen. Metafiktion im französischen und italienischen Roman der Gegenwart, Tübingen: Stauffenburg, 2003. 
steht besagter Doktor Pariani zu der Person Campanas, dessen Name wiederum in der Erzählung selbst nirgends auftaucht? Was hat es mit jenen "Erklärungen" auf sich? Welche Rolle spielt darin der Name Regolo Orlandini? Und in welcher Verbindung stehen alle Namen wiederum zu den Gedichten Campanas, aus denen offenbar zitiert wird, ohne dass dies explizit gemacht würde?

Der wichtigste Hinweis, den Tabucchi in seiner Anmerkung gibt, ist der Name Dino Campana, der den gleichen Vornamen trägt, wie der Protagonist. Dino Campana, der als "Rimbaud italiano"15 bereits zu Lebzeiten Gegenstand literarischer Legenden wurde, die nachfolgenden Dichtergenerationen mit seiner dunklen und symbolreichen Sprache begeisterte, wurde als Vorläufer einer "neuen Lyrik" und Wegbereiter des ermetismo bewundert ${ }^{16}$, wenngleich seine Bedeutung in der heutigen Kritik wesentlich vorsichtiger beurteilt wird. ${ }^{17}$

Geboren wird Campana am 20. August 1885 in Marradi, einer kleinen Stadt in der Emilia-Romagna. ${ }^{18}$ Nach dem Besuch des Gymnasiums in Faenza und Turin immatrikuliert er sich 1903 an der Universität Bologna für ein Chemiestudium. Zwei letztlich verhängnisvolle Züge seiner Persönlichkeit machen sich bereits früh bemerkbar: ein zur Labilität neigender Geisteszustand und sein Hang zum 'Nomadismus'. 1906 verbringt er erstmals einige Monate in einer geschlossenen Anstalt. Als er - auf Drängen des Vaters - vorzeitig aus der Behandlung entlassen wird, beginnt die lange Zeit des Herumirrens, auf die Tabucchis Titel anspielt.

Er schifft sich - wahrscheinlich zwischen 1907 und 1908 - nach Buenos Aires ein und zieht ziellos durch Argentinien und Uruguay. Arbeitet er zunächst als einer der zahllosen "peones de via" mit am Bau der argentinischen Eisenbahnlinien, so muss er sich späterhin mit den unterschiedlichsten Hilfstätigkeiten über Wasser halten: als Pianist in den Bordellen von Buenos Aires, fliegender Händler, Feuerwehrmann. 1909 kehrt Campana nach Europa zurück, wo er in den Jahren bis 1915 sein unstetes Leben fortführt. Er reist durch Frankreich, Belgien und die Schweiz, gelangt bis nach Russland (Odessa), verbringt einige

15 Edoardo Sanguineti (Hrsg.), Poesia italiana del Novecento. 2 Bde., Torino: Einaudi, 1993; Bd. 2, S. 727.

16 Vgl. Manfred Lentzen, Italienische Lyrik des 20. Jahrbunderts. Von den Avantgarden der ersten Jabrzebnte zu einer "neuen Innerlichkeit”, Frankfurt a. M.: Klostermann, 1994, S. 71 ff.

17 Zur Rezeptionsgeschichte Campanas siehe "Note per una storia della fortuna di Campana", in: Antonio Corsaro, Marcello Verdenelli, Bibliografia campaniana (1914-1985), Ravenna: Longo, 1985, S. 9-29. Siehe auch Francesco Bernadini Napoletano (Hrsg.), Dino Campana nel Novecento. Il progetto e l'opera, Roma: Officina, 1992; Anna Rosa Gentilini (Hrsg.), Dino Campana alla fine del secolo, Bologna: Soc. Ed. Il Mulino, 1999.

18 Biographische Angaben nach Carlo Pariani, Vite non romanzate di Dino Campana scrittore e di Evaristo Bonicelli, Firenze: Vallecchi, 1938; Ruggero Jacobbi, Invito alla lettura di Dino Campana, Milano: Mursia, 1976; Gianni Turchetta, Dino Campana. Biografia di un poeta, Milano, 1985; Sebastiano Vasalli, La notte della cometa. Il romanzo di Dino Campana, Torino: Einaudi, 1998 (EA 1984). 
Monate in einem Brüsseler Gefängnis und in einer Irrenanstalt in Tournay. Zwischenzeitlich taucht er immer wieder bei seinen Eltern oder Verwandten in Florenz auf. Dort auch knüpft er seine ersten literarischen Kontakte, insbesondere zu den Kreisen um die damals tonangebenden Zeitschriften La Voce und Lacerba. 1915 meldet er sich freiwillig zum Militär, wird jedoch abgewiesen. Er nimmt zeitweilig sein Studium wieder auf, bricht es wieder ab, verfällt dem Alkohol, setzt seine Wanderungen fort. Um 1918 verschlechtert sich Campanas körperlicher und geistiger Zustand so sehr, dass er in die psychiatrische Anstalt auf Castel Pulci eingewiesen werden muss, wo er nach mehr als einem Jahrzehnt Klinikaufenthalt am 1. März 1932 im Alter von nur 46 Jahren stirbt.

Für die Literaturgeschichte ist Campana mit einem einzigen Buch relevant geworden: den 1914 erschienenen Canti Orfici, einer faszinierenden Mischung aus (Prosa-)Gedichten und lyrischen Tagebuchskizzen, einem Hauptwerk der italienischen Lyrik im 20. Jahrhundert. ${ }^{19}$ Tabucchi baut zahlreiche Motive und Zitate aus diesem Buch in seine Erzählung ein, verwoben mit Elementen der Biographie des Autors. Eine zentrale Rolle spielt in diesem Zusammenhang der in der zitierten Anmerkung erwähnte Doktor Pariani. Dieser auch künstlerisch interessierte Arzt und Psychologe hat Campana zwischen 1926 und 1930 auf Castel Pulci viele Male aufgesucht und die langen Gespräche aufgezeichnet. Nach Campanas Tod hat er die Aussagen des Dichters kommentiert und, zusammen mit denen eines weiteren Patienten, eines Bildhauers, 1938 veröffentlicht. ${ }^{20}$ Dieses Buch blieb Jahrzehnte lang die fast einzige biographische Quelle zu Campana, und ist als solche auch weiterhin unentbehrlich, wenngleich die Aufzeichnungen Parianis, bei aller Sensibilität in künstlerischen Fragen, gleichwohl durch das erklärte Ziel des Arztes, psychoanalytische Ursachenforschung zu betreiben, bestimmt werden. ${ }^{21}$

Die Gespräche mit dem Arzt mögen Campana bei der Aufarbeitung seiner ihn in der Zeit auf Castel Pulci zunehmend quälenden Vergangenheit durchaus geholfen haben. Doch hatte er dafür auch ein anderes Mittel zur Verfügung: seine Träume. ${ }^{22}$ Der erste Satz von Tabucchis Anmerkung verweist denn auch

19 Dino Campana, Canti Orfici, Marradi: Tipografia F. Ravagli, 1914; eine erweiterte Fassung erschien vierzehn Jahre später: ders., Canti Orfici ed altre liriche. Opera completa. Firenze: Vallecchi, 1928; s.a. Dino Campana, Canti Orfici. Die Tragödie des letəten Germanen [Nachdruck der Erstausgabe von 1914], Firenze: Libr. Chiari, 2002; vgl. ferner Anm. 28.

20 Carlo Pariani, Vite non romanzate di Dino Campana scrittore e Evaristo Bonicelli sculture, Firenze: Vallecchi, 1938; der Campana betreffende Teil wurde zusammen mit einer Brief-Auswahl späterhin mehrmals neu herausgegeben. Ich zitiere hier nach Carlo Pariani, Vita non romanzata di Dino Campana. Con un'appendice di lettere e testimonianze. A cura di Cosimo Ortesta, Firenze: Ponte alle Grazie, 1994.

21 Pariani, Vita (wie Anm. 20), S. 23 und 35.

22 Vgl. Neuro Bonifazi, Dino Campana, Roma: Ed. dell'Ateneo \& Bizzarri, zweite, erw. Auflage 1978, S. 7. 
nicht nur auf den Fiktionalitätsstatus des Textes, wie die deutsche Übersetzung suggeriert. Tabucchi benutzt bewusst die Doppeldeutigkeit des Wortes “immaginario" 23 , um auch das für die Erzählsituation des Textes zentrale Traummotiv aufzurufen. So wäre Vagabondaggio das nachträgliche Protokoll eines solchen (ebenso fiktiven wie imaginären) Traumes, wie ihn Campana gegenüber seinem ärztlichen Gesprächspartner beschrieben haben mag. ${ }^{24}$

Was die existentielle Bedeutung des Traums für Campana betrifft, begegnet Tabucchi hierbei gewissermaßen einem Wahlverwandten. So heißt es zu Beginn der Erzählung Rätsel aus der Sammlung Kleine Missverständnisse obne Bedeutung (EA 1985): "Manchmal leuchtet uns eine Lösung nur auf diese Weise ein: im Traum. Vielleicht weil die Vernunft feige ist, weil es ihr nicht gelingt, die Leere zwischen den Dingen zu füllen [...]." 25 Der Traum vermöge diese Lücken in den rationalen Entwürfen zu füllen. ${ }^{26}$ Dieser Technik bedient sich Tabucchi, der übrigens in dem Band Sogni di sogni (Palermo: Sellerio, 1992) das Prinzip der literarischen Träume historischer Persönlichkeiten von Daedalus bis Sigmund Freud fortgesetzt hat, in seinen Erzählungen auf unterschiedlichen Realitäts- und Zeitebenen, wobei die narrative Struktur auf komplexe Weise zwischen den Bereichen Traum und Realität, Vergessen und Bewusstsein wechselt.

Tabucchi manages the 'mecanics' of dream-presentation in many different ways, and when there are no explicit markers to indicate the beginning and ending of a dream sequence, he differentiates the dreams stylistically and linguistically from the rest of the narrative, and offers brief but suggestive indicators which will make the reader aware of the excursion into dream. ${ }^{27}$

Um meine These von Vagabondaggio als (literarischem) Traumprotokoll zu verdeutlichen, ist es zunächst notwendig, Campanas eigene Texte in die Betrachtung einzubeziehen.

"Ich erinnere mich an eine alte Stadt mit roten Mauern und vielen Türmen, ausgesengt auf der endlosen Ebene im heißen August, die ferne Kühlung grüner

23 Siehe den Text der Anmerkung in Anm. 12.

${ }^{24}$ Der Anfang der Erzählung ("Manchmal begann es auf diese Weise, mit einem kaum wahrnehmbaren Geräusch, wie eine leise Melodie”, UK 157) ist vielleicht als verdeckte Ich-Perspektive zu sehen, entweder des historischen Dino Campana, der Pariani von seinen Träumen berichtet oder des hierüber berichtenden Pariani. Mit Beginn des zweiten Absatzes ("Er betrachtete die Reihen der Pappeln, die wie Orgelpfeifen aus der Matratze aus Nebel ragten”, ebd.) ist diese Unbestimmtheit jedoch einer eindeutigen Erzählungperspektive in der dritten Person gewichen. Zu den weiteren narratologischen Implikationen dieses Übergangs siehe unten S. $77 \mathrm{ff}$.

25 "Rätsel", in: Antonio Tabucchi, Kleine Mißverständnisse obne Bedeutung, München: dtv, ${ }^{4} 1999$, S. 21-43, S. 21; ders., "Rebus", in: Piccoli equivoci senza importanza, Milano: Feltrinelli, S. 29-46, S. 29.

26 Tabucchi, Kleine Mißverständisse (wie Anm. 25), S. 21.

27 A. L. Lepschy, "Filling the Gaps: Dreams in the Narrative Fiction of Antonio Tabucchi", in: Romance Studies 18, 1991, S. 55-64, S. 56. 
und sanfter Hügel im Hintergrund". 28 Mit diesem Satz aus dem langen, aus verschiedenen Einzeltexten bestehenden Prosagedicht Die Nacht (La Notte) - dessen Titel zugleich der der ersten, aus sechs Prosagedichten bestehenden Abteilung des Buches ist - setzen die Orphischen Gesänge ein. Es ist charakteristisch für die Anlage des gesamten Buches wie Campanas Poetik überhaupt, dass die Erinnerungsformel des "Ich erinnere mich ..." am Anfang steht. ${ }^{29}$

Doch ist diese Bewegung kein Rückwärtsschreiten entlang einer linearen Chronologie. Sie entsteht, wie Barbara Villiger Heilig in ihrem ausführlichen Nachwort zur deutschen Ausgabe beschreibt, aus der Versenkung in einen traumähnlichen Zustand ("sogno", Traum, sei daher synonym mit "ricordo", Erinnerung, zu lesen) und bedeute eine "absolute Distanzierung von der aktuellen Zeitlichkeit und Eintauchen in einen absolut anderen Bereich". ${ }^{30}$ So heißt es einige Zeilen weiter in La Notte: "und auf einmal mitten aus dem toten Wasser die Zigeunerinnen, ein Gesang, ein anfängliches Klagelied, eintönig, quälend: und aufgehoben wurde der Gang der Zeit". ${ }^{31}$ Die historische Zeit wird stillgestellt und alles spielt sich fortan in einem Raum der Erinnerung ab. Der Eröffnungsabschnitt des Buches verschafft den Zutritt hierzu; er besitzt "Schwellenfunktion". ${ }^{32}$ Die berühmte Formulierung "und aufgehoben wurde der Gang der Zeit" (“... e del tempo fu sospeso il corso") ${ }^{33}$, mit dem er endet, gibt zugleich das Zeichen zum endgültigen Eintritt in jenen 'absolut anderen Bereich', in dem das erinnernde Ich im nächsten Abschnitt bereits angelangt ist:

Unwillkürlich hob ich die Augen zu dem barbarischen Turm am Ende der langen Platanenallee. Über der wachsende Stille lebte er seine ferne und wilde Mythe, während sich mir durch ferne Gesichte, durch finstre und ungestüme Gefühle eine andere Mythe, dunkel und wild auch sie, nach und nach durch den Sinn bewegte. [...] Unwillkürlich hatte der, der ich gewesen war, sich aufgemacht nach dem barbarischen Turm, dem mythischen Wächter der Jugendträume. ${ }^{34}$

28 Ich zitiere aus der deutschen Übersetzung: Dino Campana, Orphische Gesänge. ItalienischDeutsch. Übertragen von Hanno Helbing. Mit einem Essay von Barbara Villiger Heilig, München, Wien: Hanser, 1995, S. 9. Weiterhin maßgeblich ist die italienische Werkausgabe von Enrico Falqui von 1973, die neben den Canti Orfici verstreut erschienene Texte sowie zahlreiche Briefe enthält: Opere e contributi, a cura di Enrico Falqui. Prefazione di Mario Luzi. Note di Domenico De Robertis. Carteggio a cura di Niccolò Gallo, 2 Bde., Firenze: Valecchi, 1973. Eine ausgezeichnete Werkeinführung und Strukturanalyse bietet Alberto Asor Rosa, "Canti Orfici di Dino Campana”, in: ders. (Hrsg.), Letteratura italiana. Le Opere (Vol. IV), Il Novecento. 1. L'età della crisi, Torino: Einaudi 1995, S. 333-404. Einen ausführlichen Einzelkommentar bietet: Dino Campana, Canti Orfici. Poesie commentate da M. Caronna, Messina: Rubbetino, 1993.

29 Teresa Ferri, Dino Campana. L'infinito del sogno, Roma: Bulzoni, 1985, S. 45.

30 Barbara Villiger Heilig in: Campana, Orphische Gesänge (wie Anm. 30), S. 207-251, S. 233.

31 Campana, Orphische Gesänge (wie Anm. 28), S. 9.

32 Villiger Heilig (wie Anm. 30), S. 232.

33 Campana, Orphische Gesänge (wie Anm. 28), S. 8.

34 Campana, Orphische Gesänge (wie Anm. 28), S. 9 und S. 11. 
Was Tabucchi nun tut, ist nicht anderes, als diese raumzeitliche Dynamik hin auf jene "Jugendträume" auf die Konstruktion von Vagabondaggio zu übertragen und hierbei sogar den unmittelbaren Beginn seiner Erzählung dem 'incipit' der Canti Orfici nachzubilden:

Manchmal begann es auf diese Weise, mit einem kaum wahrnehmbaren Geräusch, wie eine leise Melodie; und auch mit einer Farbe, einem Fleck, der in den Augen entstand und sich über der Landschaft ausbreitete; und dann legte sich der Fleck wieder auf die Augen und ging von dort auf die Seele über: Indigo zum Beispiel. Indigo hatte den Klang einer Oboe und an besonders glücklichen Tagen den einer Klarinette. Gelb klang hingegen wie eine Orgel. (UK 57)

Am Ende der sich pendelartig und letztlich aus den Augen des Träumers heraus synästhetisch erweiternden Bewegung hat mit diesem auch der Leser seine Position gewechselt und ist unmerklich von der Ebene des historischen Dino Campana hinüber in die Traumwelt des Dino Artista geglitten. Wie in den Canti Orfici markiert der folgende, zweite Absatz der Erzählung diesen Übergang. Die gelben Orgeltöne werden nun als Sonnenuntergang 'rematerialisiert' und das dem träumenden Dino Campana verschwimmende Bewusstsein erscheint dem geträumten alter ego als realer Nebel:

Er betrachtete die Reihen der Pappeln, die wie Orgelpfeifen aus der Matratze aus Nebel ragten, und darüber sah er die gelbe Musik des Sonnenuntergangs, in die sich ein paar goldene Töne mischten. Der Zug durchquerte die Landschaft, der Horizont war ein unbeständiger Faden, der inmitten der Nebelschwaden auftauchte und wieder verschwand. (UK 157) ${ }^{35}$

Dabei enthält die Formulierung "Manchmal begann es auf diese Weise ..." zwei Hinweise: zum einen markiert sie den Wiederholungscharakter jener Träume des realen Campanas, gewissermaßen ihre 'ewige Wiederkehr'. Zum anderen - und dies ist mit Blick auf die Engführung von Traum und Erinnerung in den Canti Orfici ebenso wichtig - meint dieser Satz auch das Aleatorische und Unwillkürliche eines sich innerhalb einer gewissen Variationsbreite immer wieder neu gestaltenden Traumvorgangs. (Im eigenen Verständnis erscheint Tabucchis Text damit als eine "iterative Erzählung" im Sinne Genettes. ${ }^{36}$ )

Im Blick des lyrischen Ich auf den "mythischen Wächter der Jugendträume", "la mitica custode dei sogni dell'adolescenza"37, sind Lethe und Mnemosyne

35 Mit den musikalisch-farblichen Synästhesien verweist Tabucchi implizit (s. auch UK 166) auf einen für Campana zentralen Stilaspekt. Pariani zufolge hat Campana erklärt, er habe, anregt von u.a. der französischen Literatur (Baudelaire, Nerval, Verlaine, Rimbaud), einen zuvor fehlenden (modernen) Sinn für Farben in die italienische Dichtung eingeführt ("di avere introdotto il senso dei colori (alla moderna) nelle patrie lettere"; Pariani, Vita, wie Anm. 18, S. 74). Siehe auch Maura del Serra, "Evoluzione degli stati cromatico-musicali", in: Dino Campana oggi. Firenze: Vallecchi, 1973, S. 86-108.

36 Vgl. Gérard Genette, Erzählung (wie Anm. 9), S. 83. Dieses iterative Moment ("Manchmal begann es auf diese Weise ...") ließe sich auch als Beginn eines Berichts über einen wiederkehrenden psychotischen Zustand plausibel machen, wobei das “es” eben jener Zustand wäre, von dem der Psychiater (Pariani) berichtet.

37 Campana, Orphische Gesänge (wie Anm. 28), S. 11 bzw. 10. 
nicht voneinander zu trennen, ein Gedanke, der Campana sicherlich bereits von Nietzsche her vertraut war, dessen begeisterter Leser er war. Das Vergessen ist auch bei diesem bereits die Bedingung des Erinnerns, die die Suche nach den Orten einer untergegangenen Kindheit ohne die Kontrollinstanz des Bewusstseins ermöglicht. ${ }^{38}$ So sind die Canti Orfici im Kern eine halluzinatorische Reise des Wanderers Campana mit dem Ziel einer Verwandlung in einen "uomo nuovo"39, einen "neuen Menschen". Dieser Initiations- und Erneuerungsprozess, den das lyrische Ich durchläuft (mit zahlreichen Anspielungen auf mythische bzw. literarische Figuren oder historische Persönlichkeiten wie Dionysos, Orpheus, Dante, Leonardo da Vinci, Hamlet oder Faust) und den Tabucchi mit seiner Erzählung nachzugestalten sucht, wird zur mystischen Reise, bei der es vielerlei Übergänge zu bewältigen gibt. ${ }^{40}$ Um jedoch ihren Fortgang und damit auch den der Erzählung im einzelnen zu untersuchen, benötigen wir einen weiteren zentralen Prätext, durch den ihr Tabucchi ihr zentrales Motiv zuführt: die Reise als Selbsterkenntnis.

Campana hat, wie soeben erwähnt, Nietzsches Philosophie intensiv rezipiert, wie die vielen Motive, Zitate und Ideen aus dem Werk des Philosophen in Campanas Gedichten und Briefen belegen. ${ }^{41}$ Auch folgender Text aus dem zweiten Band von Menschliches, Allqumenschliches (228. Aphorismus) hätte deshalb Campana ohne weiteres bekannt sein können:

Reisende und ihre Grade. - Unter den Reisenden unterscheide man nach fünf Graden: die des ersten niedrigsten Grades sind solche, welche reisen und dabei gesehen werden, - sie werden eigentlich gereist und sind gleichsam blind; die nächsten sehen wirklich selber in die Welt; die dritten erleben etwas infolge des Sehens; die vierten leben das Erlebte in sich hinein und tragen es mit sich fort; endlich giebt es einige Menschen der höchsten Kraft, welche alles Gesehene, nachdem es erlebt und eingelebt worden ist, endlich auch nothwendig wieder aus sich herausleben müssen, in Handlungen und Werken, sobald sie nach Hause zurückgekehrt sind. Diesen fünf Gattungen von Reisenden gleich gehen überhaupt alle Menschen durch die ganze Wanderschaft des Lebens, die niedrigsten als reine Passiva, die höchsten als die Handelnden und Auslebenden ohne allen Rest zurückbleibender innerer Vorgänge. ${ }^{42}$

38 Vgl. Erich Kleinschmidt, "Vergessenheit. Überlegungen zu einer amnestischen Kulturtheorie in Friedrich Nietzsches Also sprach Zarathustra", in: arcadia 36, 2001, 1, S. 100-117.

39 Vgl. Lentzen, Italienische Lyrik (wie Anm. 16), S. 73.

40 Nach dem Vorbild der Divina Commedia Dantes sollte sie sich in drei Etappen vollziehen. Die ersten beiden Sektionen Notte/Nacht und Nottorni/Nachtstücke würden dann dem Inferno entsprechen. Diese Konzeption wird jedoch nur im Ansatz erkennbar, möglicherweise weil Campana sein Gedichtbuch nicht ganz zum Abschluss bringen konnte (vgl. hierzu Lentzen, Italienische Lyrik, wie Anm. 16, S. 74 ff.).

41 Siehe hierzu "Campana e Nietzsche", in: Bonifazi, Dino Campana (wie Anm. 22), S. 19-74, sowie aktueller Flavia Stara, "L'orfismo nietzscheano e Campana", in: dies., L'incanto orfico, Bari: Palomar, 1997, S. 73-108.

42 Friedrich Nietzsche, Menschliches, Allzumenschliches (II. Band), in: ders., Sämtliche Werke. Kritische Studienausgabe. München: dtv [u. a.], 1999 (im folgenden zitiert als KSA), Bd. 2, S. 483-484. 
Diesen Aphorismus zitiert Silvio Ramat in dem Campana gewidmeten Kapitel seiner 1976 erschienenen Storia della poesia italiana del novecento im Zusammenhang mit der Erörterung des Reisemotivs. ${ }^{43}$ Der Dichter der Canti Orfici, so Ramat, sei dabei jedoch keinem bestimmten jener Grade bei Nietzsche zuzuordnen. Vielmehr habe er als gegensätzlich bestimmte und von Gegensätzen angezogene Persönlichkeit sowohl Anteil am ersten wie am letzten Grad; seine Sprache sei Ausdruck einer vorgeblichen blinden Passivität, schlage aber immer wieder in eine 'orphische', visionäre Ausdrucksweise um. ${ }^{44}$

Da Antonio Tabucchi selbst Literaturwissenschaftler ist, was man bei der Lektüre seiner Texte nie vergessen sollte, dürfte bei seinen eigenen Recherchen zu Campana in Ramats Standardwerk auf diesen Aphorismus gestoßen sein, sofern er ihn nicht aus eigener Nietzsche-Lektüre kannte. Meine These im folgenden ist jedenfalls, dass genau dieser Aphorismus, in Verbindung vielleicht sogar mit der Bewertung Ramats, nicht nur die Grundidee zu Vagabondaggio lieferte, sondern darüber hinaus der Erzählung selbst als teleologische Strukturfolie unterlegt wurde.

Zunächst entspricht das Motiv der Reise wiederum einer grundlegenden Disposition von Tabucchis eigener Poetik und ist, wie dasjenige des Traumes, in fast all seinen Texten präsent ${ }^{45}$, so auch in Vagabondaggio. Nicht nur Dino Artistas (bzw. Campanas) Leben ist von Reise und Wanderung bestimmt. Ebenso gilt dies für die beiden Nebenfiguren, den Sensale und Regolo, die jedoch im Gegensatz zu ihrem Schützling sehr zielbewusst handelnde, gewissermaßen professionelle Reisende sind. Zugleich ist auch auf der Ebene des discours die Erzählung als Reise angelegt, nämlich als Reise in die Imagination und Erinnerung. Worauf es Tabucchi jedoch eigentlich ankommt, ist die Reise als existentielle Metapher, wie sie auch die Struktur der Canti Orfici selbst bestimmt.

Dies wird bereits an Details der Dialogführung deutlich. So antwortet Dino Artista zu Beginn auf die unvermittelte Frage des Sensale, warum er gerade diesen Zug genommen habe, in den er offensichtlich in völliger Unkenntnis von dessen Bestimmungsort gestiegen sei: "Einfach um zu fahren [...], weil Züge fahren" (UK 158). Doch statt über eine solch redundante Antwort verwundert zu sein, antwortet sein Begleiter nicht minder enigmatisch: "Sicher, Züge fahren, und wir fahren mit ihnen” (UKA 158). Immer wieder durchbrechen so die Erzählfiguren in den Dialogen Tabucchis ihre Fiktionalitätsebene. ${ }^{46}$

\footnotetext{
43 Silvio Ramat, "L’intenzione regressiva dei "Canti orfici”,, in: ders., Storia della poesia italiana del novecento, Milano: Mursia, 1976, S. 115-128, S. 117.

44 Vgl. Ramat, Storia, wie Anm. 43, S. 117.

45 Reisen durchziehen das Werk Tabucchis in metaphorischer und konkreter Bedeutung. Hierbei spielt das gesamte Wortfeld 'Eisenbahn', samt Wagons, Bahnhöfen, Gleisen, Wartesälen etc., eine zentrale Rolle (vgl. Kurtz, Die Literatur im Spiegel ihrer selbst, wie Anm. 5, S. 304 ff.).

46 Vgl. Kurtz, Die Literatur im Spiegel ihrer selbst (wie Anm. 5), S. 330 ff.
} 
Von hier lässt sich nun der Bogen zum Aphorismus und der darin beschriebenen "Wanderschaft des Lebens" bzw. deren erster Stufe schlagen. Denn die Reisenden "des ersten niedrigsten Grades" sind ja nach Nietzsche solche, "welche reisen und dabei gesehen werden - sie werden eigentlich gereist und sind gleichsam blind". ${ }^{47}$ Dieses Moment der Passivität wie des dabei Beobachtetwerdens (durch den Sensale) trifft genau auf die anfängliche Situation des Dino Artista zu. Doch ändert sich nach der Begegnung mit dem Viehhändler erstmals die bisherige Dynamik seiner Existenz. Denn durch die Einladung nach Modena erhält er die Möglichkeit, jenen ersten Grad der "reine[n] Passiva"48 zu überschreiten, indem er mit dem Sensale - zunächst in einer Kutsche - eine neue Stadt erkundet. Dabei bedeutet der Umstieg vom Zug in die bedächtig trabende Kutsche für Dina Artista zwar eine Verlangsamung der Fortbewegung, was jedoch auch als Ausdruck einer fortan bewussteren Wahrnehmung der Umwelt zu werten wäre.

Die Figur des Sensale ist bei diesem hier (im zweiten von insgesamt sechs Kapiteln) einsetzenden "Bildungsprozess" des Protagonisten, ebenso wie die Regolos, auf eine besondere Art symbolisch besetzt. So müssen wir deshalb ein weiteres Stück ins intertextuelle Gefüge des Textes eindringen. Denn innerhalb der Semantik dieses 'Traumes' sind jene beiden Männer mehr als Erzählfiguren. Sie sind zugleich als Manifestation zweier grundsätzlich verschiedener und zugleich sich ergänzender Existenz- und Denkprinzipien kodiert, des Dionysischen und Apollinischen. Dabei wird jedoch zu beachten sein, dass Tabucchi bei seiner poetische Konkretisierung der Dualität weniger auf Nietzsches Theorem zurückgreift als vielmehr ursprünglich antike Elemente mit einbezieht.

So führt der lebenslustige Viehhändler nach der Stadtrundfahrt Dino zunächst in sein Stammlokal, wo sie zur Begrüßung, als übliches Geschenk des Hauses, sogleich eine Karaffe Wein erhalten (vgl. UK 160). Doch genügt dies natürlich, gemeinsam mit der Tatsache, dass es in der antiken Überlieferung neben dem Dionysos-Typ des schönen, jungen Mannes auch den früheren des älteren, fülligen und bärtigen Mannes gibt, noch nicht als Beleg, um den Makler als travestierten Dionysos zu enttarnen. Als beide jedoch nach einiger Zeit die schwüle Atmosphäre des Lokals verlassen, weist der Sensale seinen Schützling darauf hin, dass an jenem Februar-Abend die Karnevalszeit zu Ende gehe. Nun fand das Fest der Anthestrien, eines der beiden traditionellen Kultfeste zu Ehren des Dionysos, gleichfalls im Februar statt und wie der Gott einst auf einem Schiffskarren symbolischen Einzug hielt, war in der Erzählung auch sein etwas profaneres Traumbild per Kutsche genüsslich in Modena 'eingezogen'.

Wenn schließlich am Ende dieser 'Prozession', die in der griechischen Tradition stets auch eine phallisch-orgiastische war, Dionysos/Sensale - als Gott

\footnotetext{
47 Nietzsche, Menschliches, Allzumenschliches, wie Anm. 42, S. 483.

48 Nietzsche, Menschliches, Allzumenschliches, wie Anm. 42, S. 484.
} 
nicht nur des Weines, sondern auch der Ekstase und Fruchtbarkeit - seinen neuen 'Jünger' nach dem Besuch des Restaurants in ein Bordell (ein)führt, scheint die Parodie auf den antiken Kult perfekt zu sein. Empfangen vom Gekicher einer weiblichen Gesellschaft, die (in der Rolle der Mänaden?) ihren Stammgast begrüßt, folgt für Dino nun der Übergang zum "dritten Grad” und zugleich seine sexuelle Initiation.

Zu diesem dritten Grad gehören Nietzsche zufolge all jene Reisenden, die nicht nur wie die des zweiten "wirklich selber in die Welt [sehen]"49, sondern darüber hinaus etwas erleben "infolge des Sehens" 50 , also bloße Wahrnehmung in Erfahrung umformen. Das mag man Dino Artista nach seinem ersten Tag in Modena und insbesondere der sich anschließenden Nacht nicht abstreiten. Auch der darauffolgende Tag mit den Eindrücken des Viehmarkts lässt sich für den noch naiven jungen Protagonisten als erfahrungsreich in Nietzsches Sinn beschreiben. ${ }^{51}$ Wenn der Sensale dann am Ende des Marktes Dino mit seinem Freund Regolo bekannt macht, bildet der hagere fahrende Händler, der in Begleitung eines Papageien reist, nicht nur körperlich einen starken Kontrast zum Sensale. Eine Aura der Strenge umgibt ihn; mit einem wortlosen Händedruck begrüßt er Dino. Gleichwohl verbindet diese Figur mit dem Viehhändler eine unausgesprochene Vertrautheit und als jener ihm Dino mit den Worten anvertraut: "Paß eine Zeitlang auf ihn auf, er erinnert mich an meinen Sohn, er ist Künstler und heißt Dino" (UK 163), bedarf es scheinbar keiner weiteren Erklärungen.

Auf der Suche nach einer Vorlage für diese Figur bei Campana stößt man zunächst auf eines seiner bekanntesten Prosagedichte: "L'incontro di Regolo" / "Begegnung mit Regolo". ${ }^{52}$ Kenner Campanas werden natürlich sofort versuchen, hier eine Verknüpfung herzustellen. Doch hebt Tabucchis Anmerkung zur Erzählung diese Vermutung wieder auf, denn: "Auch wenn Regolo Orlandini in den 'Erklärungen' Campanas vorkommt, die von Doktor Pariani aufgezeichnet wurden, ist er hier eine frei erfundene Figur” (UK 168). Und in der Tat haben der fiktive und der historische Regolo nicht mehr gemein als Vornamen und Beruf, auch wenn hier, wie oftmals, Vorsicht gegenüber Tabucchis in den Paratexten

\footnotetext{
49 Nietzsche, Menschliches, Allzumenschliches, wie Anm. 42, S. 483.

50 Nietzsche, Menschliches, Allzumenschliches, wie Anm. 42, S. 483.

51 Die Erzählung blendet jedoch die Zeit nach dem Eintritt ins Bordell aus und setzt erst nach dem Schließen des Marktes wieder ein. Mit den Erzählverfahren Tabucchis vertraute Leser wissen, dass solche häufig vorkommenden 'Ellipsen' nicht zufällig sind und auf den Einfluss der Filmästhetik verweisen. So sei der Film eine besondere Form, den Träumen Gestalt zu verleihen, meint Tabucchi im Interview, und auch theoretisch habe er mehr aus z. B. Eisensteins Buch über die Montage als aus Propps Märchenanalysen gelernt (Borsari, Cos’è una vita, wie Anm. 11, S. 9 f.).

52 Campana, Orphische Gesänge (wie Anm. 28), S. 163-68.
} 
gelieferten Hinweisen geboten ist. ${ }^{53}$ Wie "frei erfunden" auch immer: diese Figur wird von Tabucchi nicht willkürlich eingesetzt, sondern gewissermaßen mythisch verankert, denn sie dient dazu, Dionysos 'Gegenspieler' Apoll, besser gesagt das Prinzip des Apollinischen, manifest werden zu lassen.

Apoll ist in der griechisch-römischen Mythologie eine Gottheit mit vielen Gesichtern: Gott des Lichts (dem Ursprung nach), Schicksalsgott und Hüter des Orakels von Delphi. Für die abendländische Kultur am wichtigsten dürfte er in seiner Eigenschaft als Apoll Musagetes, als Musenführer und damit auch Gott der Künste geworden sein. Insofern ist er bereits aus dieser Rolle heraus der geeignete Begleiter Dino Artistas, der seine junge Künstlerschaft mit nun entstehenden (und in der Erzählung selbst thematisierten) Versen im Dialog mit Regolo unter Beweis zu stellen sucht.

Apoll bildete (auch als Gott der Ordnung und Klarheit) bereits in der Antike den natürlichen Widerpart zum ekstatischen Dionysos. So hatte die Paarung bzw. die hiervon abgeleiteten Adjektivformen, als Nietzsche sie 1871 in der Geburt der Tragödie aus dem Geiste der Musike erstmals als psychologische und ästhetische Leitbegriffe seines Denkens erwähnte, bereits eine lange anthropologische Vorgeschichte.

Apollinisch sind hiernach Traum und Vision, das harmonisch Geordnete und die Begrenzung durch Weisheit, Dionysisch alles leidenschaftlich Bewegte, das Grenzüberschreitende und Grenzen-Zerbrechende, der Rausch, die Ekstase, in der Kunst vor allem als Musik und Lyrik. ${ }^{54}$ Bezogen auf Campana nannte Mario Bejor "das Apollinische und das Dionysische die beiden Grundmomente seiner pendelnden poetischen Existenz". ${ }^{55}$ Und Neuro Bonifazi führt hierzu weiter aus:

Due perciò sono gli elementi complementari dell'arte: ebrezza e sogno; l'ebrezza dà il gesto, la passione, il canto, la danza, è la forza della natura, è lo spirito dionisiaco, è la musica, la melodia di Campana; il sogno dà la facoltà di riunire, la rappresentazione, il sogno caden-

53 Zu Pariani sagt Campana: "Il Regolo dell’Incontro è uno che andò in Argentina. Si chiamava: Regolo Orlandelli, era di Mantova. Lo incontrai in Argentina, a Bahia Blanca. Prima l'avevo conosciuto presso Milano. Viaggiava il mondo. In America aveva un'agenzia di collocamento, a Milano faceva il commercio ambulante" (Pariani, Vita, wie Anm. 20, S. 58; [Der Regolo aus "Begegnung" ist einer, der nach Argentinien ging. Er hieß: Regolo Orlandelli, er war aus Mantova. Ich traf ihn in Argentinien, in Bahia Blanca. Zuvor hatte ich ihn in der Nähe von Mailand getroffen. Er reiste um die Welt. In Amerika besaß er eine Stellenvermittlung, in Mailand war er als fahrender Händler unterwegs]; Übersetzung RDB).

54 Siehe zur Rezeption dieser Paarung im europäischen Kontext den Artikel von Barbara von Reibnitz (u. a.), "Apollinisch - dionysisch", in: Karlheinz Barck, Friedrich Wolfzettel (Hrsg.), Ästhetische Grundbegriffe. Historisches Wörterbuch in sieben Bänden. Bd. 1: Absenz - Darstellung, Stuttgart [u. a.]: Metzler, S. 246-271.

55 "L'apollineo e il dionisiaco sembravano i due momenti stessi del suo pendolare vivere poetico" (Mario Bejor, Dino Campana a Bologna 1911-1916. Bagnacavallo: STE, 1943; zitiert nach Bonifazi, Dino Campana, wie Anm. 22, S. 23). 
zato di Campana. Ecco spiegato il dilemma campanianio: contenuto dionisiaco, forma apollinea. ${ }^{56}$

[Die komplementären Bestandteile der Kunst sind demnach zwei: Rausch und Traum; der Rausch führt ihr die Geste, die Leidenschaft, den Gesang, den Tanz zu, es ist die Kraft der Natur, es ist der dionysische Geist, die Musik, die Melodie Campanas; der Traum führt ihr die Fähigkeit zur Einigung und Darstellung zu, der rhythmisierte Traum Campanas. So also würde sich der Zwiespalt seines Werk erklären: dionysischer Inhalt, apollinische Form.]

Was Dionysos fehlt, werde “durch Apollo zur Vollendung geführt”, schrieb bereits der schweizerische Rechts- und Kunsthistoriker Johann Jakob Bachofen 1861 in Das Mutterrecht über das Verhältnis von Dionysos und Apoll in historisch-philosophischer Perspektive. ${ }^{57}$ Übertragen auf die Erzählung Tabucchis heißt dies, dass was der Sensale im Sinn seiner ‘ästhetischen Erziehung’ Dino Artistas beginnt, im folgenden durch Regolo zum Abschluss gebracht werden soll. Der Sensale und Regolo erscheinen - von Tabucchi mit den Inhalten jener philosophischen Dualität aufgeladen - als traumhafte Repräsentanten des innersten künstlerischen Zwiespalts Campanas.

In Anbetracht solch hoher Aufgaben beginnt das folgende vierte Kapitel zunächst recht profan, nämlich mit einer Auflistung der Artikel, die der fahrende Händler im Angebot führt und bei deren Verkauf Dino ihm nun behilflich ist: "Regolo verkaufte Ritscher in allen Farben, das waren kleine Knäuel Stopfgarn; und außerdem Fortsetzungsromane, die einmal im Monat erschienen, und das Horoskop" (UK 164). Doch was zunächst nur ein beiläufiges Detail scheint, entpuppt sich bei näherer Betrachtung als Träger wichtiger poetologischer Aussagen, die hier durch eine 'mise en abyme' in die Erzählhandlung integriert wurden.

So sind die nach Farben geordneten Strähnen Stopfgarn (also keine "Knäuel") ${ }^{58}$ die innerhalb der Diegese an Dino Artista bildhaft gewordene allegorische Mahnung, seinem Leben endlich Richtung und Sinn zu geben, gewissermaßen die vielen losen Handlungsfäden zu einem konsistenten Entwurf, einem textus zusammenbringen, sich in Geschichte zu ordnen, "di ordinarsi in storia". ${ }^{59}$ Die von Regolo verkauften Fortsetzungsromane unterstützen dieses Postulat und mögen zudem an die Unabgeschlossenheit von Dino Artistas Entwicklung erinnern. Da aber Tabucchi seine Erzählungen stets auch als Medium

56 Bonifazi, Dino Campana, S. 33; Übersetzung RDB.

57 Johann Jakob Bachofen, Gesammelte Werke. Hrsg. von Karl Meuli, Bd. 3, Basel: Schwabe, S. 597 f. (zitiert nach: "Apollinisch/dionysisch", in: Joachim Ritter (Hrsg.), Historisches Wörterbuch der Philosophie. Band A-C, Basel: Schwabe 1971, Sp. 443). Hingegen feiert Bachofen 1867 in der Unsterblichkeitslehre der orphischen Theologie, "wo er die beiden Gottheiten gar die Herrscher der beiden Welthälften, der tellurischen und der uranischen, sein läßt, Dionysos als den mächtigeren" (ebd.).

58 "Regolo vendeva arruffi di tutti colori, che erano matassine di filo per rammendi" (Tabucchi, $I l$ gioco del rovescio, wie Anm. 10, S. 150).

59 Silvio Ramat, "Dino Campana", in: Gianni Grana (Hrsg.), Letteratura Italiana. Novecento. Gli scrittori e la cultura letteraria nella società italiana, Milano: Marzorati, 1982, S. 1979-2042, S. 1984. 
der poetologischen Reflexion nutzt, sind diese wiederum zugleich ein versteckter Hinweis auf seine eigene Poetik.

So vertritt Gunde Kurtz die These, dass alle zwischen 1981 und 1991 erschienenen Arbeiten, "das von Il gioco del rovescio bis Requiem entstandene Werk einen einzigen Roman" bilde, indem Themen, Motive, Situationen und Bilder, aber auch bestimmte Namen, Daten und Orte dieser Texte sich immer wieder wiederholten. ${ }^{60}$ Solche Doppelungen und Wiederholungen bewirken nach Kurtz "Spiegeleffekte" und "erhöhen so die Vertrautheit des Lesers mit Handlungsverläufen und Erzählweisen”61, so dass der Leser meine, mit jedem neu veröffentlichten Band an einem einzigen Roman weiterzulesen. Tabucchi bestätigt nicht nur in einem 1995 erschienenen Interview diese These, sondern geht sogar noch einen Schritt weiter: man müsse seine Bücher zum besseren Verständnis in ihrer ursprünglichen Reihenfolge und nicht isoliert voneinander lesen, weil jedes einzelne Teil einer globalen Weltgeschichte sei, die damit zugleich die seiner Einbildungskraft werde, und seiner Existenz als Schriftsteller wie als Mensch. ${ }^{62}$

Apoll war bekanntlich auch der Gott des delphischen Orakels und es ist wohl nur ein gradueller Unterschied, wenn Regolo auch Horoskope führt. Im italienischen Original heißen sie "pianeti della fortuna", kleine farbige Zettel mit unterschiedlichen Sprüchen und Weisssagungen, die traditionellerweise von fahrenden Händlern und Zigeunern verkauft wurden. Oftmals waren es dann dressierte Vögel oder Meerkatzen, die die Zettel auswählten und überreichten (man findet diese Tradition teilweise heute noch in südeuropäischen Ländern). Genau dies ist die Aufgabe von Regolos Papagei Anacleto. Damit wird dieser gleichsam zum Symbol für Tabucchis am Zufallstopos orientierten Schicksalsbegriff, wie er ihn (angeregt von barocken Topoi, wie auch von der Chaostheorie) insbesondere in den Erzählungen des Bandes Kleine Mißverständnisse obne Bedeutung illustriert. Kleine Unregelmäßigkeiten und die normalen Zwischenfälle des Lebens ein beiläufiger Satz, eine Geste, eine alltägliche Entscheidung - können weitreichende Wirkungen haben. ${ }^{63}$ Und wie das Leben, so werde auch die Kunst vom Zufall bestimmt: "genau darin bestand auch die merkwürdige Funktion der Kunst”, wie der Erzähler erläutert, "auf zufällige Weise in die Hände irgendwelcher Leute zu gelangen, denn alles auf der Welt ist Zufall, und die Kunst erinnert uns daran, weshalb sie uns zugleich traurig macht und uns tröstet” (UK 165f.).

\footnotetext{
60 Gunde Kurtz, “Tabucchis großer Roman”, in: Romanistische Zeitschrift für Literaturgeschichte, 1993, S. 451-62, S. 451.

61 Kurtz, "Tabucchis großer Roman” (wie Anm. 60), S. 451.

62 "Creo $[. .$.$] que para comprender mejor lo que he escrito posiblemente convenga leer mis libros$ de manera contextual y no aisladamente, y que cada uno de ellos pueda ser considerado un capítulo de una historia global que en fin de cuentas es la de mi imaginación, la de mi vida, la de mi existencia, no sólo como escritor, sino también como hombre" (Carlos Gumpert, Conversaciones con Antonio Tabucchi, Madrid: Anagrama, 1995, S. 190).

63 Vgl. "Rätsel” in: Kleine Mißverständnisse obne Bedeutung (wie Anm. 25), S. 30.
} 
In Reggio di Emilia verlässt Dino Artista seinen zweiten Mentor für einige Stunden, um - in Begleitung des Papageien - die Stadt zu besichtigen. In Analogie zum zweiten Kapitel wiederholen sich nun bestimmte Handlungselemente bzw. werden auf entscheidende Weise variiert. Beide Male erkundet Dino eine ihm bislang unbekannte Umgebung, beide Male endet der Weg in einem Lokal, dort ein Restaurant, hier ein Café (in welchem er sich mit Regolo verabredet hat). Doch wurde Dino in Modena noch vom Sensale geführt, wählt er sich nun seinen eigenen Weg. Noch beeinflussen zwar negative Gedanken seine Stimmung, noch durchwandert er - und hier zitiert Tabucchi Campanas Gedicht La petite promenade du poète - "strade / strette oscure e misteriose" 64 , dunkle und geheimnisvolle Gassen. Doch hinter deren Fenstern zeigen sich dem werdenden Dichter Dino Artista bereits "Gemme e Rose" (ebd.) ${ }^{65}$, sprießen Knospen ${ }^{66}$ und Rosen hervor, symbolischer Ausdruck vielleicht eines sich vorbereitenden Umschwungs im Lebensgefühl. ${ }^{67}$ Dino hat hiermit den vierten Grad des Reisenden erreicht: intensiv lebt er "das Erlebte in sich hinein" 68 und macht es zum Teil der eigenen Persönlichkeit, die zu einem neuen Gleichgewicht findet.

Andrej Belyji, russischer Vertreter einer Konzeption der Intertextualität 'avant la lettre', arbeitete nicht nur an der Vorstellung eines Textraumes, in den man weiterschreibend eintritt, sondern auch an der Idee einer unendlichen Kette von Korrespondenzen zwischen den Texten, zwischen Schichten von Texten, deren je neue Schicht die darunter liegende neu- und wiederschreibt. So wiederholen die Texte "Strukturen, die zuletzt im Mythos vorgeschrieben sind". ${ }^{69}$ Dies gilt auch in der hier unternommenen 'archäologischen' Annäherung an Vagabondaggio, bei der nun die nächste und letzte Schicht erreicht ist, die Gedankenwelt der antiken Orphik.

Durch Nietzsches Gegenüberstellung des Dionysischen und Apollinischen erhielt auch die Orpheus-Figur eine neue philosophisch-literarische Dimen-

${ }^{64}$ Campana, Orphische Gesänge (wie Anm. 28), S. 50.

65 "Me ne vado per le strade / Strette oscure e misteriose: Vedo dietro le vetrate / Affaciarsi Gemme e Rose" (Campana, Orphische Gesänge, wie Anm. 28, S. 50). Die Übersetzerin von Vagabondaggio, Karin Fleischanderl, greift für die identifizierten Gedichtzitate auf Helbing zurück. Dieser übersetzt hier gegenüber der klaren Syntax von Campana dem Reim zuliebe etwas manieriert und mit Blick auf "Gemme und Rose" meiner Ansicht nach wenig einsichtig: "Durch die dunklen Gassen geh ich, / durch die heimlichen und engen, / Aurea und Rosa seh ich, / die sich zu den Fenstern drängen" (S. 51).

66 'Gemma' bedeutet jedoch auch 'Edelstein'.

67 Nach seinem Spaziergang versieht Dino die verschiedenen Farben der Horoskopkarten Regolos mit eigenen Versen (UK 167). Leider waren für diese Zitate keine Vorlagen bei Campana ausfindig zu machen. Solcherlei "misleading or pseudo-markers" (Heinrich F. Plett, Hrsg., Intertextuality, Berlin, New York: de Gruyter, 1991, S. 11 f.) wären jedoch für Tabucchi nichts Ungewöhnliches.

68 Nietzsche, Menscbliches, Allzumenschliches (wie Anm. 42), S. 483.

69 Lachmann, Gedächtnis und Literatur (wie Anm. 8), S. 74. 
sion. ${ }^{70}$ Für viele Künstler, Musiker und Literaten seit der Romantik repräsentierte Orpheus einen neuen Dichtertyp zwischen Apoll und Dionysos, wurde zum Symbol des Künstlers schlechthin. Von dieser geistig-kulturellen Renaissance eines mythischen Denkmodells, von der u.a. auch Rilkes Sonette an Orpheus (1922) zeugen, blieb Campana nicht unberührt, wie bereits der Titel seiner Gedichtsammlung zeigt, der damit zugleich den auch für Campanas künstlerische Existenz bestimmenden tragischen Aspekt des Orpheus-Mythos aufruft. ${ }^{71}$

Der Begriff der Orphik bzw. des Orphischen ist jedoch zunächst religionsphilosophisch einzuordnen. Die Orphik bezeichnet eine seit dem 6. Jahrhundert v. Chr. in Attika, Unteritalien und Sizilien nachweisbare Bewegung, die durch Wanderprediger besonders in den unteren Volksschichten populär war und ihre Lehren von Orpheus herleitete. Es war eine Art esoterischer und mystischer Geheimlehre, deren Regeln nur Eingeweihten bekannt waren und die ihren Anhängern nach einem Prozess der Reinigung und Askese ein seliges Leben nach dem Tod verhieß. ${ }^{72}$ So wie Elemente dieses Denkens und dieses kulturellen Zusammenhangs in die Orphischen Gesänge eingingen, hat auch Tabucchi solche offensichtlich in die Erzählstruktur von Vagabondaggio einbezogen.

Zunächst einmal ist die Zeit mit Regolo, verglichen mit dem üppigen Lebensstil, den er beim Sensale kennen gelernt hatte, vereinfacht gesagt, ziemlich unbequem. An die Stelle von Kutschfahrten, üppigen Mahlzeiten und sinnenfrohen Bordell-Nächten treten Fußmärsche, karge Kost und Übernachtungen auf fremden Heuböden. Diese ‘asketischen' Handlungen sind Voraussetzungen jenes Reinigungsprozesses im orphischen Sinn, den Dino Artista mit Regolos Hilfe (und im geheimen Einverständnis mit dem Sensale) auf seinem Weg zu durchlaufen hat. Da nun aber die Handlung nicht im antiken Griechenland, sondern im Italien der Jahrhundertwende spielen sollte, benötigte Tabucchi ein 'moder-

70 J.L. Klein schrieb bereits 1865, an die aristotelische Definition der Tragödie durch den Katharsis-Begriff anknüpfend, dass Orpheus zum Stifter der Dionysos-Mysterien bestellt worden sei, "um den Dionysos-Dienst [...] zu läutern und auf seinen Ursprung zurückzuführen [...], auf die Einheit mit der Osirischen Sonnen-Idee und dem Seelen-Reinigungsbegriff; auf die Identität also des Dionysos mit Apollon [...] eine Katharsis, durch welche der phrygisch-thrakische Volksgott Bakchos in den geistig klaren Lebensordner und Kulturgott Apollon umgeläutert werden sollte" (zitiert nach Joachim Ritter, Historisches Wörterbuch der Philosophie, Band A-C, Schwabe: Basel 1971, Sp. 444).

71 Siehe hierzu ausführlich "L'orfismo di Dino Campana", in: Bonifazi, Dino Campana, wie Anm. 22, S. 75-134. Zur Orphik im Kontext des französischen Symbolismus siehe Flavia Stara, "La rinascita di motivi orfici nel secondo ottocento francese", in: dies., L'incanto orfico (wie Anm. 41), S. 19-46.

72 Zum Begriff der 'Orphik' siehe weiter bei Karl Kerényi, Pythagoras und Orpheus. Präludien zu einer zukünftigen Geschichte der Orphik und des Pythagoreismus, Zürich: Rhein-Verlag, ${ }^{31950 ; ~ A g o s t i n o ~ M a-~}$ saracchia (Hrsg.), Orfeo e l'orfismo. Atti del Seminario Nazionale: Roma-Perugia 1985-1991, Roma: GEI, 1993; und Johanna J. S. Aulich, Orphische Weltanschaunng der Antike und ihr Erbe bei den Dichtern Nietzsche, Hölderlin, Novalis und Rilke, Frankfurt a. M. [u. a.]: Lang, 1998. 
nes' Symbol, um diesen Prozess zum Abschluss zu bringen - und findet es im etwas abseits der Via Emilia liegenden Canossa, das durch den Bittgang Heinrich IV. im Jahre 1053 in dieser Hinsicht sprichwörtliche Bedeutung erlangte. Dort angelangt überblickt Dino von der Höhe der Burgruine die Po-Ebene und die bislang zurückgelegte Strecke seiner Reise.

Betrachtet man seine Reiseroute auf der Karte, so stellt man fest, dass alle Stationen (der Erzählung) auf einer Linie liegen, nämlich an der Via Emilia. Nur Canossa lag - notwendigerweise - abseits. Hierher musste er kommen, um seine Katharsis (und das heißt hier gleichzeitig 'Bewusstwerdung'), auf die er schrittweise vorbereitet wurde, zu vollenden. Der Horizont ist nun nicht mehr wie zu Beginn "ein unbeständiger Faden, der inmitten der Nebelschwaden auftauchte und wieder verschwand” (UK 157). Der Nebel hat sich aufgelöst und die seit der Antike bestehende Handelsstraße, die von Rimini bis Piacenza hinaufreicht, wird zur existentiellen Metapher: sie zieht sich "wie ein langes vielversprechendes Band" (UK 166) schnurgerade gen Norden Richtung Mailand. Dahinter lagen "Europa, die modernen Metropolen, voller Elektrizität und voller Werkstätten, in denen das Leben pulsierte wie Fieber" (UK 166). Somit ist die Straße eine nicht nur räumliche, sondern auch zeitliche Verbindungslinie, die den Bogen von der Antike hin zur Zukunft schlägt.

Wäre Dino Artista zu Beginn der Erzählung nicht mit dem Sensale in Modena ausgestiegen, hätte ihn der Zug letztlich in keine andere Richtung geführt. Er wäre jedoch dann, im Sinne von Nietzsches Aphorismus, weiter "gereist worden" und sein Nachname 'Artista' wäre nichts als ein zweifelhaftes Pseudonym ohne tiefere Bedeutung geblieben. Um jedoch 'wahre Künstlerschaft' zu erlangen, musste er zunächst mit dem Sensale alias Dionysos die Welt erleben und in sich aufnehmen und sich dann durch Regolo alias Apoll seiner selbst bewusst werden: "Und was mir nun auch noch als Schicksal und Erlebnis komme, - ein Wandern wird darin sein und ein Bergsteigen: man erlebt endlich nur noch sich selber". ${ }^{73}$ Dieser Satz aus dem Beginn des 3. Teils von Nietzsches Zarathustra (im Kapitel "Der Wanderer"), den Campana aus seiner wiederholten Lektüre des Buches sicherlich kannte, wird von Tabucchi erzählerisch ausgefaltet.

Die Initiation Dino Artistas hat hiermit ihren Abschluss gefunden, was auch stilistisch unterstrichen wird. Denn während er von Canossa aus die abendliche Landschaft überblickt, erhält die Sprache des Textes wieder jene synästhetische Prägung vom Anfang: "Der Himmel war gelb mit violetten Flecken. Dino hörte Oboenmusik, und er sagte es Regolo" (UK 167). Dies ist vor dem Hintergrund der Nietzsche-Rezeption Campanas natürlich auch mit Blick auf die SonnenMetaphorik im Zarathustra zu lesen, doch muss hierbei ebenso an den Begriff des 'Crepuscolarismo' (ital. 'crepuscolo' = Dämmerung) verwiesen werden. Im Umfeld dieser wichtigen Strömung in der italienischer Lyrik um 1910 wird Campana

73 Nietzsche, Also sprach Zarathustra. Ein Buch für Alle und Keinen, KSA Bd. 4, S. 193. 
oftmals gesehen. Sie widmete sich in melancholisch-idyllischer Grundstimmung den kleinen, alltäglichen Dingen und der Welt der kindlichen Erinnerungen, wodurch Autoren wie insbesondere Sergio Corazzini und Guido Gozzano ein Gegengewicht zum Wortkult D'Annunzios schaffen wollten. Zugleich war Campana selbst jedoch von D'Annunzio beeinflusst, wie seine Dichtung auch bereits Einflüsse durch die aufkommende futuristische Dichtung erfuhr. So ist Campana nicht nur stilistisch, sondern von seiner gesamten Haltung her ein Autor des Übergangs zwischen dem Weltbild des 19. und dem des 20. Jahrhunderts, zwischen Dekadentismus und Visionismus. Er nimmt somit eine Schwellenstellung ein, die Campana, so Gianni Turchetta, selbst bewusst gewesen sei ${ }^{74}$ :

Egli è cosciente di trovarsi, rispetto alla letteratura italiana, proprio in una posizione zarathustrianamente ambigua: di essere insomma un "tramonto", la fine di molte cose (di molte forme, di molti vezzi tematici e stilistici), in un certo senso l'ultimo possibile rappresentante di una tradizione, quella "carducciana", morente; ma anche, e per gli stessi motivi, un "alba", un mattino, l'apertura di un spazio nuovo di poesia. ${ }^{75}$

[Er ist sich bewusst, sich gegenüber der italienischen Literatur in einer, aus der Sicht Zarathustras, zwiespältigen Lage zu befinden: ein "Untergang" zu sein, das Ende vieler Dinge (vieler Formen, vieler thematischer und stilistischer Eigenarten), in gewisser Hinsicht der letztmögliche Repräsentant einer sterbenden Tradition, jener "im Stile Carduccis"; zugleich aber, und aus denselben Gründen, auch eine "Morgendämmerung", ein Morgen, die Öffnung eines neuen Raumes der Dichtung.]

Dino Artista jedenfalls ist nun als "neuer Mensch" in den höchsten, den fünften, Grad der Reisenden aufgestiegen und gehört Nietzsche zufolge zu jenen wenigen Menschen "der höchsten Kraft, welche alles Gesehene, nachdem es erlebt und eingelebt worden ist, endlich auch notwendig wieder aus sich herausleben müssen, in Handlungen und Werken, sobald sie nach Hause zurückgekehrt sind". ${ }^{76}$ Hier ist die zyklische Anlage der Erzählung im romantischen Motiv der Heimkehr bereits vorgegeben. Damit ist nun auch Regolos Aufgabe erfüllt.

Es ließe sich noch mit weiteren Details belegen, wie sehr Tabucchi die Gedankenwelt und Poetik Campanas in Vagabondaggio einbezieht. Dies gilt auch für das Verhältnis der Erzählung zum biographischen Hintergrund Campanas. So befällt beim Gedanken an das fiebrig-pulsierende Leben in den Städten des Nordens zum Beispiel Dino Artista selbst ein fiebriges Gefühl: "Auch Dino hatte Fieber, es tobte hinter seinen Schläfen wie an jenem Tag, als er im Bahnhof von Bologna in den Zug eingestiegen war, von Fernweh getrieben" (UK 6). Doch was auf der Ebene der Erzählung als einfaches Reisefieber semantisiert wird, hat seine eigentliche Ursache in der historischen Realität des auf Castel Pulci internierten Dina Campana, von der die Interpretation ausgegangen war.

\footnotetext{
74 Zum Einfluss D’Annunzios auf Campana bzw. zu den futuristischen Elementen siehe in: Corsaro/Verdenelli, Bibliografia campaniana (wie Anm. 17), S. 83-98 und S. 99-129.

75 Turchetta, Dino Campana (wie Anm. 18), S. 167; Übersetzung RDB.

76 Vgl. oben das Zitat aus: Nietzsche, Menschliches, Alliumenschliches (wie Anm. 42), S. 483.
} 
In der Anstalt war Campana zuletzt zu einer recht stabilen inneren Ausgeglichenheit gelangt. Sein Leben fließe eintönig und ruhig dahin, heißt es in einem Brief vom März 1931. ${ }^{77}$ Auch mit dem ausgebliebenen literarischen Erfolg schien er sich, wenn auch verbittert, abgefunden zu haben. Doch im Februar des darauffolgenden Jahres erleidet er einen plötzlichen Rückfall in die alten Krankheitssymptome. Campana versucht aus der Anstalt auszubrechen und verletzt sich hierbei an einem Stacheldrahtzaun. Es ist nur ein leichte Wunde, die er sich zuzieht, mit jedoch fatalen Folgen, denn an der hieraus resultierenden Blutvergiftung und dem hohen Fieber wird Campana wenige Tage später sterben.

Tabucchi verweist also mit dem homodiegetischen Motiv des Fiebers gleichzeitig implizit zurück auf die als heterodiegetische Rahmenstruktur angedeutete Realität des Jahres 1932, bzw. diese dringt über das Motiv des Fiebers in den Traum ein und wird dort im kausalen Zusammenhang integriert. So übersetzt er, freudianisch gesprochen, den "Weckreiz" in die Dimensionen des Traumsymbols. Die Erlebnishorizonte des 'geträumten', im Aufbruch sich befindenden jugendlichen Dino Artista und des ihn träumenden, doch vielleicht bereits im Sterben liegenden und (träumend) auf sein Leben zurückblickenden Dino Campana verbinden sich.

“Cos'è una vita se non viene raccontata?", was sei ein Leben, wenn es nicht erzählt werde, habe Tabucchi sich häufig selbst gefragt. Vielleicht gebe es Menschen, die in der Welt seien, ohne sich das eigene Leben zu erzählen, doch sei dies so, als erlebten sie ein unbestimmtes Nichts, einer Art sich vorwärtsbewegender Amöbe gleich. ${ }^{78}$ Denn zu den frühgewonnenen Einsichten Tabucchis gehört auch die Überzeugung von der Erinnerungsfunktion der Literatur, "che la letteratura es en gran parte memoria". ${ }^{79}$ Wenn Pariani also seinen psycho-pathologischen Bericht über Campana und den Bildhauer Bonicelli Vite non romanzate, als nicht erzählte/'vertextete' Leben betitelte ${ }^{80}$, dann liegt genau hierin die Motivation für Tabucchis "micro-romanzo". ${ }^{81}$ Ein Element fehlt deshalb noch in der hier unternommenen philologischen Ausgrabungsarbeit. Die (von Tabucchi rekonstruierte) Geschichte Campanas wäre nicht vollständig ohne einen Hinweis auch auf die fast tragisch zu nennende Entstehungsgeschichte der Canti Orfici.

\footnotetext{
77 Brief vom 9. März 1931 an den Bruder Manlio: “[...] La mia vita scorre monotona e tranquilla. Leggo qualche giornale. Non ho più voluto occuparmi di cose letterarie stante la nullitá dei successi pratici ottenuti. Il mercato librario in Italia è assolutamente nullo per il mio genere [...]”" (zitiert nach: Dino Campana, Souvenir d'un pendu. Carteggio 1910-1931 con documenti inediti e rari, a cura di Gabriel Cacho Millet, Napoli 1985, Brief CLXXII, S. 244).

78 "Forse ci sono persone che vivono senza raccontarsi la propria vita. Ma è come se vivessero un nulla indistinto. Una specie di ameba che si sposta, che si muove" (Borsari, Cos'è una vita, wie Anm. 11, S. 6).

79 Gumpert, Conversaciones (wie Anm. 62), S. 49.

80 Siehe Anm. 18.

81 Vgl. Kurtz, Die Literatur im Spiegel ibrer selbst (wie Anm. 5), S. 270.
} 
Als Campana sich 1913 kurzzeitig in Florenz aufhält, nimmt er Kontakt auf zu Ardengo Soffici und Giovanni Papini, den Herausgebern von Lacerba, jener florentischen Zeitschrift, die in den darauffolgenden Jahren fast so etwas wie das offizielle Organ des italienischen Futurismus werden sollte. Soffici erinnerte sich später daran, wie Campana aus seiner Tasche ein verschlissenes und schmutziges Notizbuch gezogen habe, solcherart "wie sie Makler [Hervorhebung von mir, RDB] und Gutsverwalter verwenden, um ihre Rechnungen zu verzeichnen und ihre Einkäufe und Einnahmen zu notieren" 82 , und es Papini übergab. Es war das Originalmanuskript der soeben fertiggestellten Canti Orfici. Papini wie Soffici lasen es und waren auf Anhieb begeistert von diesen Gedichten, die sie sogleich als Buch veröffentlichen wollten. Campana hatte jedoch die Stadt in der Zwischenzeit wieder verlassen und war nicht mehr ausfindig zu machen. Erst ein Jahr später tauchte er plötzlich auf und forderte sein Manuskript zurück. Leider vergeblich, denn Soffici, in dessen Verwahrung die Blätter gewesen waren, fand es - durch einen zwischenzeitlichen Umzug bedingt, wie er dem aufgebrachten Dichter zu erklären versuchte - nicht wieder.

Es sollte verschwunden bleiben, ein für Campana bis zu seinem Tod traumatischer Verlust. Mühevoll und letztlich vergeblich machte er sich nun daran, aus dem Gedächtnis und nach noch vorhandenen Entwürfen, die ursprüngliche Fassung zu rekonstruieren. (Er veröffentlicht dann das neue Buch 1914 mit dem deutschen Untertitel Die Tragödie des letzten Germanen in Italien - auf eigene Kosten. ${ }^{83}$ ) Noch über Jahre hin wird er versuchen - mit zunehmender Aggressivität und Verzweiflung - von den Verlegern die Herausgabe seines Manuskripts zu fordern. ${ }^{84}$ Als Erfahrung, so Tabucchi, sei dies für den Dichter schlimmer als die spätere Isolation in der Anstalt gewesen, da der Verlust des Buches auf bestimmte Weise den Verlust einer ganzen, darin aufgehobenen, Existenz bedeute, ein Unglück, durch das er sich dem Autor zutiefst verbunden fühle. ${ }^{85}$

In seinen Träumen durchlebte der internierte Campana sein Leben immer aufs Neue, um immer wieder aufzubrechen und wieder heimzukehren, "un continuo

82 "Tirò fuori di tasca un vecchio taccuino coperto di carta ruvida e sporca, di quelli dove i sensali e i fattori segnano i conti e gli appunti delle loro compere e vendite, e lo consegnò a Papini”" (zitiert nach Ramat, Letteratura Italiana, wie Anm. 59, S. 1981).

83 Siehe den Literaturhinweis in Anm. 19. Zu den Hintergründen des deutschen Untertitels und der Widmung an den deutschen Kaiser Wilhelm II. siehe bei Alberto Asor Rosa, Letteratura Italiana (wie Anm. 28).

84 "Se dentro una settimana non avrò ricevuto il manoscritto e le altre carte che vi consegnai tre anni sono verò a Firenze con un buon coltello e mi farò giustizia dovunque vi troverò" ["Wenn ich nicht innerhalb einer Woche das Manuskript und die anderen Papiere, die ich Euch ausgehändigt habe, zurückerhalte, werde ich nach Florenz kommen und mir mit einem ordentlichen Messer Gerechtigkeit verschaffen, wo immer ich Euch finde"; Übersetzung RDB]; Brief an Giovanni Papini vom 23. Januar 1916, zitiert nach: Campana, Souvenir d'un pendu (wie Anm. 77), S. 134.

85 Vgl. Gumpert, Conversaciones (wie Anm. 62), S. 150. 
partire e un continuo ritornare". 86 Diese permanente Erinnerungsschleife ist Ausdruck auch der Suche nach dem bereits einmal Schrift gewordenen Gedächtnis, "il dramma della memoria umana che ha perduto, o non ha acquistato, la facoltà di ordinarsi in storia"87, das Drama der menschlichen Erinnerung, die er einst verlor oder niemals erwarb, die Fähigkeit, sich als Geschichte und in einer Geschichte zu ordnen. Indem nun Tabucchi den Protagonisten seiner Erzählung in das Jahr 1906 zurückversetzt, einen Zeitpunkt also, da der historische Dino überhaupt erst an den Canti Orfici zu schreiben beginnt, vollzieht er dies nach und versetzt den Dichter virtualiter zurück in die Lage, jenes Buches und damit die eigene Identität in ihrer ursprünglichen Form zu verwirklichen. Das "Manchmal begann es auf diese Weise ..." des Anfangs von Vagabondaggio ist letztlich auch Hinweis auf diese traumhaft immer wieder unternommene Suche. ${ }^{88}$

Zwar geht darin Dino Artista auf dem ihm nunmehr bewusst gewordenen Weg weiter. Doch durch das einmontierte Campana-Zitat "Rauhes Präludieren dumpfer Musik, zitternder Geige mit elektrisches Saite, Straßenbahn, die entlang einem Strang am eisernen Himmel gewundener Drähte läuft ...” (UK 169) ${ }^{89}$, auf das bereits zu Beginn der Erzählung angespielt wird (UK 159), kommt eine die Dimension des Traumes sprengende Sinnebene hinzu. Deutlicher wird dies durch den unmittelbar anschließenden letzten Satz: "Los Dino, geh schneller, lauf weit weg, das Leben ist klein und viel zu weit die Seele” (UK 168). Er gibt dem Text einen versöhnlichen Abschluss mit einer vielleicht etwas kitschigen metaphysischen Note, wodurch Tabucchi jedoch eine weitere Konstituente der Poetik Campanas in seinen Traumtext integriert, wie sie Tera Feri in L'infinito del sogno beschreibt:

Passato e futuro, realtà e sogno, vita e morte, conoscenza e ignoranza, silenzio e parola: l'avventura logorante e salvifica degli Orfici deve necessariamente toccare questi poli perché dalla morte si generi un'altra vita, che non sia rifiuto o abbandono passivo, ma accettazione e volontà di procedere. ${ }^{90}$

86 Bonifazi, Dino Campana (wie Anm. 22), S. 7.

87 Ramat, Letteratura Italiana (wie Anm. 59), S. 1984.

88 Was Tabucchi nicht thematisiert: 1971 fand sich die verschollene Erstfassung überraschend im Nachlass Sofficis wieder. Nach der Veröffentlichung des Manuskripts unter dem ursprünglichen Titel Ilpiù lungo giorno (Dino Campana, Ilpiù lungo giorno. Testo critico a cura di Domenico De Robertis, Firenze: Vallecchi, 1973) musste man jedoch bald feststellen, dass "die Neufassung der Canti orfici einen bei weitem reiferen und vollendeteren Eindruck hinterlässt" (Lentzen, Italienische Lyrik, wie Anm. 16, S. 73). Zur Textgenese siehe ausführlich E. Falqui, "Per una cronistoria dei Canti orficl”, in: Campana, Opere e contributi (wie Anm. 28), S. 125-260.

89 Tabucchi zitiert hier den Anfang des Prosagedichts "In der Straßenbahn nach Amerika und wieder zurück” (Campana, Orphische Gesänge, wie Anm. 28, S. 157-161, S. 158).

90 Ferri, L'Infinito del sogno (wie Anm. 29), S. 50; Übersetzung RDB. Durch den impliziten Verweis auf die reale Krankengeschichte Campanas würde Vagabondaggio mit dem nicht geringen Anspruch auftreten, den letzten Traum des Dichters darstellen zu wollen. Entstanden ist die Erzählung wahrscheinlich anlässlich des 100. Geburtstags Campanas im Jahr 1985. 
[Vergangenheit und Zukunft, Wirklichkeit und Traum, Leben und Tod, Wissen und Unwissenheit, Schweigen und Wort: das aufzehrende und Rettung verheißende Abenteuer der Canti Orfici muss notwendigerweise an diese Gegensätze rühren, damit aus dem Tod heraus ein anderes Leben entstehe, welches nicht Verweigerung oder passive Selbstaufgabe ist, sondern Annahme und Wille zum Fortschreiten.]

Dies sind die beiden Pole der “orphischen” Dichtung, wie sie auch von Tabucchi mit in die Konstruktion seiner Erzählung aufgenommen und in der chiastischen Konstruktion des letztes Satzes nochmals fokussiert werden: Erinnerung und Vision. Der Dichter steigt wie Orpheus in die Welt der Schatten der Vergangenheit hinab und lässt sie wieder lebendig werden, indem er in der Sprache einen neuen Blick auf die Welt und die Dinge in ihr einübt. Im Imperativ dieses Satzes überlagern und verschachteln sich die Stimmen der Erzählung: er ist homodiegetische Selbstanrede des Protagonisten Dino Artista, Handlungsanweisung des fiktiven Traumregisseurs Dino Campana und schließlich einfühlsamer Auf- und Nachruf des Autors Antonio Tabucchi, für den die Figur Campanas auch zur Projektionsfläche der eigenen künstlerischen Identität wird: “Wenn Tabucchi Tabucchi

definieren sollte?' - 'Einer, der sich sucht und auch in Zukunft immer suchen wird." "91

91 “'Se Tabucchi dovesse definire Tabucchi?' - 'Uno che si cerca e continuerà sempre a cercarsi”" (Paolo Gaglianone, Marco Cassini, Conversazione con Antonio Tabucchi. Dove va il romanzo?, Roma: Omicron, 1995, S. 34). Von Gumpert nach der Entstehung von Vagabondaggio und der anschlieBenden Erzählung "Una giornata a Olimpia" (die sich mit Pindar beschäftigt) befragt, antwortet Tabucchi, dass ihm beide Dichter nicht nur ästhetisch, sondern auch als menschliche Gestalten sehr nahe stünden. Im Falle Campanas, weil er einer seiner festen Überzeugungen entspreche, dass nämlich die großen Künstler eine unglückliche Existenz führten, und in der Tat habe Campana dieses Unglück und Leiden auf eine besonders dramatische Art durchlebt (vgl. Gumpert, Conversaciones, wie Anm. 62, S. 149). - Vor einiger Zeit hatte ich Gelegenheit, Tabucchi auf meine These von der Verwendung des Nietzsche-Aphorismus anzusprechen. Er war sichtlich überrascht, bestätigte mir dann jedoch meine Vermutung. Dino Campana selbst sei zum letzten und höchsten der fünf Grade der Reisenden zu zählen. 